\title{
Methodology for Assessing the Impact of Workplace Ergonomic Factors on Airport Security Screener's Reliability and Performance
}

\author{
Jan Zýka \\ University College of Business in Prague \\ Ivo Drahotský \\ University of Pardubice
}

Received: 11 April 2019. Revision received: 28 May 2019. Accepted: 30 May 2019

\begin{abstract}
The article deals with the questions of the connection of the working environment ergonomics to the effectiveness of security screening in air transport. The main objective of the research is to improve aviation safety by optimizing the working conditions for operators screening. Therefore the authors recommend methodological procedures for assessing the influence of ergonomic parameters of the working environment on the screening performance and reliability. In order to meet the stated goal, HODERG method and expert analysis were the most important managerial or scientific methods that have been used. The result is the proposed methodology that should serve as a managerial tool for assessing ergonomic risks in relation to the protection of air traffic against unlawful acts. A necessary prerequisite without which the main aim could not be fulfilled was the fulfilment of the objectives of the partial ones, which at the same time aimed at enriching the scientific knowledge in the related scientific disciplines such as an identification of the set of ninety measurable parameters of working environment that could potentially affect the performance or reliability of the security screener and their analysis. The possibilities of application of the methodology were experimentally verified at the international Václav Havel Airport Prague.
\end{abstract}

Key Words: security checks, security screening, ergonomics, working environment, methodology, air transport.

JEL Classification: L93, R41

\section{Introduction}

The air transport is legally considered to be the most modern, most comfortable and the fastest way to overcome long distances. Thanks to the effective approach to risk management and implementation of the desired countermeasures is at the same time statistically the safest mode of transport. Thanks to the global dimension, however, it is attractive for more than four billion passengers every year, but it is also sensitive to potential attacks whose primary goals are to come through security barriers, create feelings of fear, and, in the final consequences, to disrupt the economy of the airport operators, airlines, states or regions concerned.

To maintain the privilege of "the safest" it is necessary to continuously analyse and to improve approaches to safety issues both on the operational safety side, and also on the side of protection of air transport and its critical infrastructure against acts of unlawful interference - air transport security. 
An integral part of security nets there are security checks for passengers, luggage, air cargo and staff. The security screening is an element of the security checks, which is represented by application of technical or other means of detecting potentially dangerous objects that may be used by the attackers for the unlawful acts. The effectiveness and reliability of the screening depends, inter alia, on the type of X-ray equipment used, the spatial layout of the site, the additional technical equipment and, in particular, the quality of the worker's screening.

In an imaginary "race" of the most advanced technology for detecting potentially dangerous passengers and prohibited items or optimizing passengers flows by modifying the procedures or screening workplaces there has been neglected the factor, which finally decides whether the air transport will be safe or not - a human - with all his positive and negative properties. The human factor is represented at several levels in an airport management system. The strategic one ensures the fulfilment of legal and regulatory standards, the tactical has the role of organizational and supervisory and the operational performs the executive operational functions of the airport. And exactly the operational level is represented by airport security screeners. Considering the key role of screener, the critical parameter of the optimum is his reliability, which is represented by performance and error rates when detecting prohibited and potentially dangerous objects hidden or forgotten in a luggage. To be able to perform tasks with the highest confidence, it is necessary to identify work environment factors that could influence this reliability in order to minimize them subsequently.

The paper is divided into six main parts. The Introduction is followed by the Literature review, which describes who deals with the optimization of screening and optimization of the working environment in the world. The Methodology describes the sub-goals of the research and the key methods used to achieve these goals. The Achieved results chapter outlines the outputs that have been achieved through proven research. Discussion mainly analyses the weaknesses and risks associated with the application of the developed Methodology, while Conclusion describes the managerial benefits of the Methodology as well as the contribution to the science.

\section{Literature review}

According to the IATA (2016) the annual traffic in approximately 4 billion passengers and this figure has been increasing yearly since 1950, albeit with slight fluctuations due to objective factors (Figure 1). In 2014, the IATA published the expected development of passenger air traffic between 2014-2034 at the International Conference in Athens (IATA, 2014). This document predicts an average stable growth in demand for air travel of $3.9 \%$ per year, with the optimistic option even counting with an annual growth of $5.6 \%$ of passengers. However, it is clear that in such a globalized sector sensitive to unpredictable world events, the influence of various negative factors can be felt and the projected growth may be in the future for a short period weakened. According to the Airport Council International (ACI), security costs represent an average of $20 \%$ of the total operating costs of airport operators in Europe (ACI Europe, 2015). 


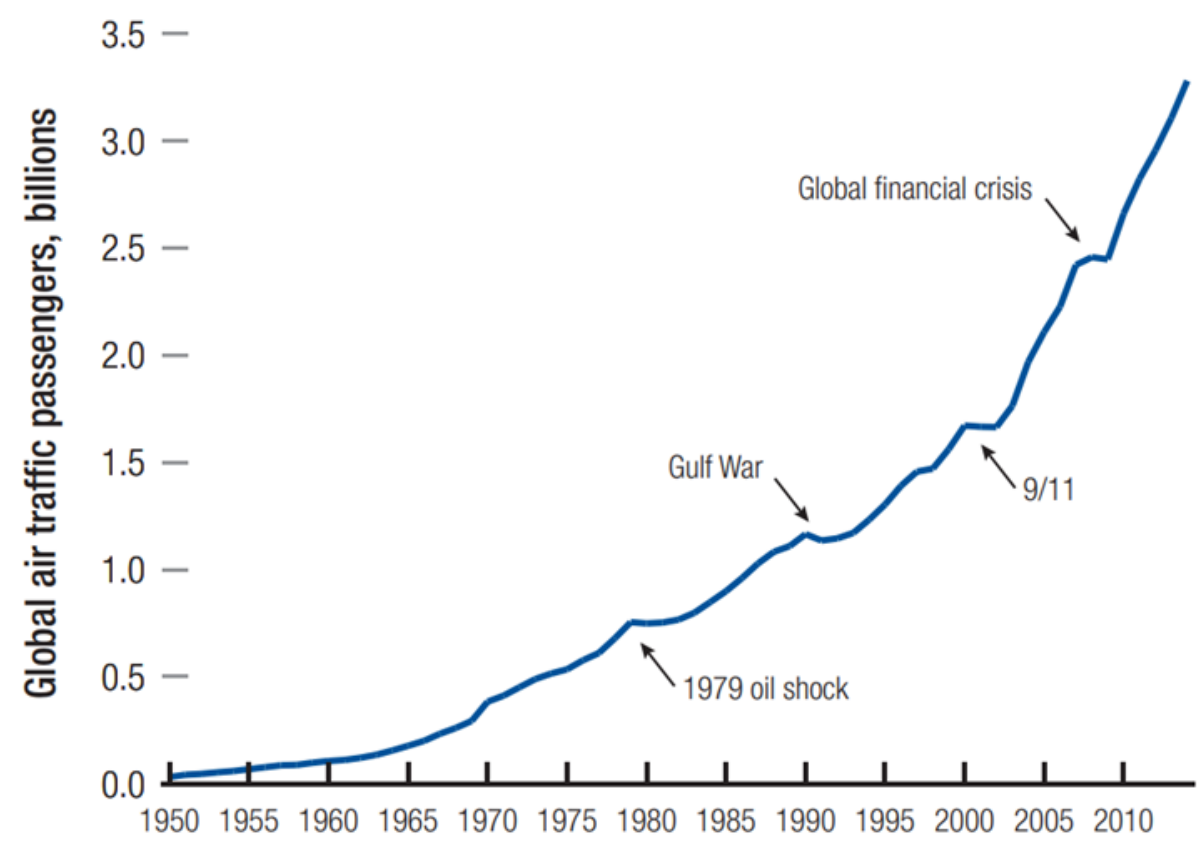

Source: (Oxley and Jain, 2015)

Based on these data, it is clear that the optimization of the security control process is a highly actual topic, which needs to be addressed and investigated systemically on several lines.

In summary, the approaches to implementing optimization measures at the airport security screening process focus primarily on increasing the throughput of passengers through security controls, assessing the ergonomics of the workplace's spatial solution to reduce the physical load on the operators, increasing the intensity of routine or random security checks (Croucher, 2013) or research into the possible use of behavioural analysis procedures (Kittinger \& Bender, 2015) to differentiate passengers for multi-step security control within the IATA Smart Security project (IATA, 2013). The influencing of the operators' working conditions to the reliability of the screening is not dealt in air transport or other critical infrastructure. For the research it was therefore necessary to adopt the theory and practical implementation in the fields related to optimizing the reliability of working activities in terms of ergonomics of different workplaces outside the original field of research - air transport.

It has been found that when looking into the ergonomic design of workspaces, it is necessary to respect the principles of a set of ISO standards and standard methods of measurement and evaluation of physical and chemical factors in the work environment, which are addressed by The National Institute of Public Health. The literary research also shows a general interest in solving the issue of human-machine interaction in relation to human factor failure and its reliability in relation to the conditions at the workplace (European Agency, 2013; Stolk, 2012; European Agency 2009). And The Framework Agreement on Work-related Stress is also worth mentioning (Svaz průmyslu a dopravy, 2004), which was signed by representatives of European employees and employers. It describes that "... all employers have a legal obligation to protect the safety and health of workers. This obligation also applies to stress-related working situations, provided that it presents a risk to health and safety. " The goal for the employer is to evaluate whether there is a stress presented in the workplace. If so, then he should look for ways to eliminate 
it. However, this 2004 agreement has not yet been transposed into the national legislature of the Czech Republic. Its implementation was planned to the Labor Code in 2017, but finally Labor Code Act No. 262/2006 Coll. has not been amended.

Closer to the topic of the study there is the project "Evaluation of the impact of the working environment of the block supervisors of industrial plants on the reliability of operator's performance" (Skřehot et al., 2015), as it concerns the evaluation of the working environment factors, their relation to the performance and the error rate of the personnel using the human-machine interaction in the work tasks. Its principles have served as one of the inputs in the development of specific methods of the research. In general, we can build on the basic vision of IATA Smart Security, which aims to improve the environment and experience for passengers during security checks. It can be assumed that the improvement of the passenger environment can also have a positive impact on the personnel carrying out the control. The means how to achieve this goal is the construction of the workplaces themselves with respect to the passengers, not the identification and minimization of the negative factors of the working environment of the operators. The BEMOSA final report (BEMOSA, 2013), which mentions "security decisions depend on employees", provided a stimulus to perform research at the workers/screeners themselves.

The influence of illumination on performance is discussed in a study by $\mathrm{Hu}, \mathrm{Yi}$, Hao, Qiao, and Guo (2018), who, in experimens, explores the influence of illumination and color temperature on a sample of students. Systemic capabilities how to improve performance through human resource management are discussed by Banks, Mosier, Robertson, Honan and Cascio (2017). According to them, one of the basic building blocks for keeping existing workers is to create a quality working environment, respecting both mandatory and optional ergonomic principles. This is very important in a sector that is bound to work with scarce resources, such as airport screening operators with relatively large degree of fluctuations. The next article (Van der Voordt \& Jensen, 2017) discusses the issue of workplace performance assessment, defining twelve evaluation parameters focusing on in-house processes, economic and social parameters, and ergonomic indicators.

The authors made a simplified pilot study at Václav Havel Airport Prague in the early stages of the research, asking by anonymous questionnaires the screening operators for their work environment. The published results (Drahotský and Zýka, 2014) indicate, among other things, that $80 \%$ of respondents from 40 respondents complained, for example, about too high or low temperature and temperature fluctuations at deployed workplaces within the airport. The intensity of illumination, the number of monitors, or light advertising makes it harder to concentrate $55 \%$ of operators, $42.5 \%$ of workers are bothering excessive noise and $40 \%$ of odour. There have been no changes to the working environment since 2014 and it can be concluded that the data obtained are still up to date.

Based on the analysis of the current state of issue, it is obvious that the subject of the research has not yet been fully solved at domestic and foreign universities. According to the above assessment, the realization of the optimization measures of man-machineenvironment relations is desirable, which is being realized by more and more companies here and in the world as well. In addition to traditional Occupational Safety and Health $(\mathrm{OSH})$ systems, they come with the application of methods for identifying ergonomic risks, evaluating them and introducing optimization measures. They aim at improving the quality of working life of employees, which can be expressed in terms of health, social, economic and production, ie reduction of occupational injuries or occupational diseases, elimination of discomfort and work well-being, reduction of the cost of treatment of 
employees or reduction of loss due to their absence and increase of employee motivation and performance (Moore, 2001).

On this basis the aim of the research was set: "Methodology for assessing the impact of workplace ergonomic factors on airport security screener's reliability and performance" (further in the text as Methodology).

\section{Methods}

In order to meet the stated goal, it was necessary to carry out some partial steps in order to fulfil the partial goals of the research:

1. To create a model of the screening checkpoint with the representation of the spatial arrangement of workplaces in relation human-machine-environment and a description of work tasks carrier by security screener and chronology of the tasks.

2. To identify sets of measurable ergonomic criteria and parameters of work environment.

3. To specify criteria for evaluating selected parameters.

4. To perform expert analysis

5. To determine the weights of the individual parameters based on the performed expert analysis.

6. To define intervals for values of defined work environment parameters.

7. To specify the degree of ergacity for defined interval values of the defined parameters.

8. To complete the Methodology for assessing the impact of workplace ergonomic factors on airport security screener's reliability and performance

9. To develop a proposal for the implementation of the Methodology for the operation of an international airport.

10. To carry out a risk analysis for applying the Methodology.

11. To define benefits of the Methodology for relevant scientific disciplines and operational practices

This chapter also gives an overview of the most important managerial or scientific methods that have been chosen for the study, including a description of their specific use in the next steps leading to the fulfilment of the stated goals.

\subsection{HODERG method}

The HODERG method, according to Král (2001), is used to assess the ergacity according to a range of criteria and parameters, which can determine work well-being in a human-machine-environment evaluation system.

The applicability of this method is limited by the following assumptions, which also outline the partial steps leading to its application:

- The ergatic level is measurable, i.e. it is possible to objectively determine the parameters, their units, the values of these units and the method of measurement.

- If the ergatic level is objectively unmeasurable, the verbal scale or relative scale, expressed as a percentage, is determined.

- It is possible to formulate ranges of ergacity to determine the limits of threats of individual ergatic criteria.

- It is possible to evaluate the significance of the influence of individual criteria and parameters on the weight by means of an expert method. 
- It is possible to determine empirical dependencies that appropriately capture the linking of elements with the differentiation of significance of criteria and parameters (i.e. weights).

The ergacity of the system can be in interval $<0 ; 1>$ and it's determined by the relation:

$$
E_{s}=\frac{\sum_{i=1}^{i=k} E_{k i} \cdot V_{k i}}{\sum_{1}^{k} V_{k i}}
$$

where:

Es ... the ergacity of the system

$E k i \ldots$ index of ergacity of the i-th category of criteria $\langle 0 ; 1\rangle$

$V k i$... the weight of the i-th criteria

$k$... number of evaluated criteria

\subsection{Expert analysis}

According to Trevelyan (2014), the expert method is "a means for carrying out expert analysis in the process of solving expert problems". Expert algorithms can be considered as algorithms or methods that can effectively solve expert problems and provide credible answers to expert questions. Authenticity subsequent expert evaluation is affected by many factors, including the quality of input data and the level of expertise and professionalism of experts and their ability to interdisciplinary thinking system.

\section{Results}

The expert's assessment of the persons involved in the system of security inspections at airports or experts dealing with working conditions and environment is used for the solution. Specifically, verbal-numeric, correspondence and anonymous techniques were used. Classification of the degree of ergacity of defined Epi parameters is the output of a partial solution.

The analysis was carried out in the form of an assessment of ergatical significance, in which the experts were asked to score the established criteria/parameters of the workplace in relation to the expected degree of correlation with concentration, performance or possible error in the implementation of assigned work activities in the human-machine-environment system. Experts were also able to optionally add a comment to each criterion or parameter. The assessment was conducted in electronic form via an interactive sheet of the MS Excel software. Ten experts were addressed, with the return and completing of the required data of $60 \%$. Of the 564 total expected values, 558 were recovered, in six cases the experts were not able to evaluate the given parameter from their position. The scoring results are shown in Figure $2-$ after the cluster analysis into nineteen criteria in the form of mean values of ergatic significance $g k i$. 
Figure 1 Global air passenger traffic trend 1950-2014

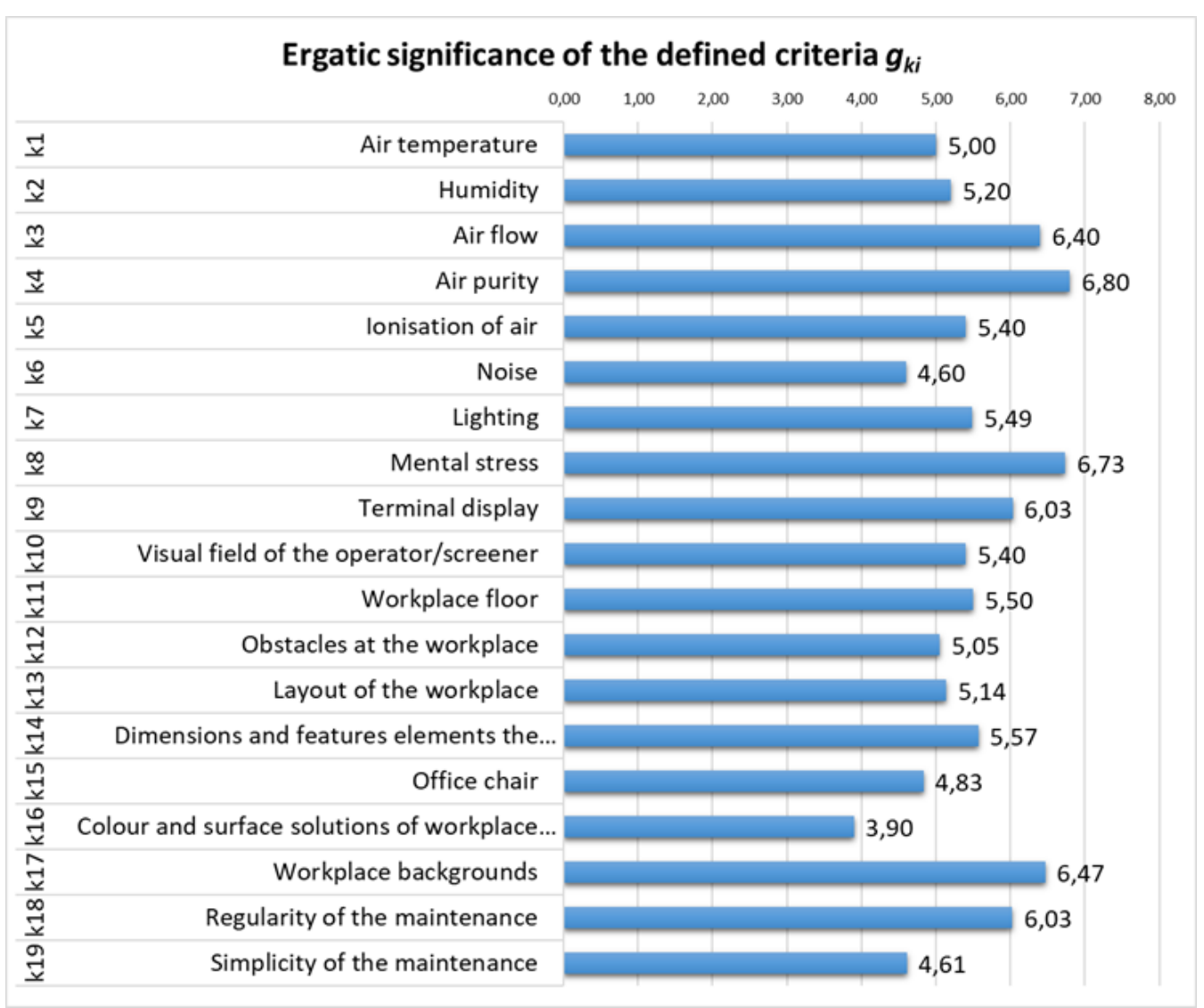

Source: authors

The output of the analysis is the determination of the weighting of the defined parameters Vpi. Ergatic significance was transposed on weights by an exponential relationship (2) that better reflects the difference in results and assigns greater weight to more significant parameters:

$$
V_{p i}=2^{g_{p i}-1}
$$

Based on this relationship, the scale shown in Table 1 was realized. 
Table 1

The scale of the conversion of the ergatical significance to the weighting of the parameters

\begin{tabular}{|c|c|}
\hline $\begin{array}{c}\text { Mean value of the ergatical } \\
\text { significance of the parameter } \boldsymbol{g}_{\boldsymbol{p} \boldsymbol{i}}\end{array}$ & Parameter weight $\boldsymbol{V}_{\boldsymbol{p} \boldsymbol{i}}$ \\
\hline $\mathbf{0 , 0 0 - \mathbf { 0 , 4 9 }}$ & 0,5 \\
\hline $\mathbf{0 , 5 0}-\mathbf{1 , 4 9}$ & 1 \\
\hline $\mathbf{1 , 5 0}-\mathbf{2 , 4 9}$ & 2 \\
\hline $\mathbf{2 , 5 0}-\mathbf{3 , 4 9}$ & 4 \\
\hline $\mathbf{3 , 5 0}-\mathbf{4 , 4 9}$ & 8 \\
\hline $\mathbf{4 , 5 0}-\mathbf{5 , 4 9}$ & 16 \\
\hline $\mathbf{5 , 5 0}-\mathbf{6 , 4 9}$ & 32 \\
\hline $\mathbf{6 , 5 0}-\mathbf{7 , 4 9}$ & 64 \\
\hline $\mathbf{7 , 5 0}-\mathbf{8 , 0 0}$ & 128 \\
\hline
\end{tabular}

Source: authors based on HODERG method

\subsection{Technical experiment}

The objective of the technical experiment conducted by the authors was to point out possible formal shortcomings in the way of measurement, values recording or evaluation of the obtained data. The experiment was carried out at the Vaclav Havel Airport Prague. The degree of ergacity of the evaluated criteria (Table 2), the categories (Table 3) and the workplace as a whole were obtained by recording the identified and indicatively measured values of the defined parameters and the subsequent calculation.

Table 2 Established values of defined ergacity criteria at the evaluated workplace

\begin{tabular}{|c|l|c|}
\hline & Name of the criteria & $\boldsymbol{E}_{\boldsymbol{k}}$ \\
\hline$E_{k 1}$ & Air temperature & 0,96 \\
\hline$E_{k 2}$ & Humidity & 1,00 \\
\hline$E_{k 3}$ & Air flow & not rated \\
\hline$E_{k 4}$ & Air purity & not rated \\
\hline$E_{k 5}$ & Ionisation of air & not rated \\
\hline$E_{k 6}$ & Noise & 0,87 \\
\hline$E_{k 7}$ & Lighting & 0,81 \\
\hline$E_{k 8}$ & Mental stress & 0,83 \\
\hline$E_{k 9}$ & Terminal display & 0,68 \\
\hline$E_{k 10}$ & Visual field of the operator/screener & 0,79 \\
\hline$E_{k 11}$ & Workplace floor & 1,00 \\
\hline$E_{k 12}$ & Obstacles at the workplace & 0,93 \\
\hline
\end{tabular}




\begin{tabular}{|c|l|c|}
\hline$E_{k 13}$ & Layout of the workplace & 1,00 \\
\hline$E_{k 14}$ & $\begin{array}{l}\text { Dimensions and features elements the workplace and the } \\
\text { location of the controls }\end{array}$ & 0,83 \\
\hline$E_{k 15}$ & Office chair & 0,96 \\
\hline$E_{k 16}$ & Colour and surface solutions of workplace materials & 1,00 \\
\hline$E_{k 17}$ & Workplace backgrounds & 1,00 \\
\hline$E_{k 18}$ & Regularity of the maintenance & 0,78 \\
\hline$E_{k 19}$ & Simplicity of the maintenance & 0,70 \\
\hline
\end{tabular}

Source: authors

Table 3 Established values of defined ergacity categories at the evaluated workplace

\begin{tabular}{|l|l|c|c|}
\hline & Name of the category & Calculation & $\boldsymbol{E}_{\boldsymbol{k} \boldsymbol{a}}$ \\
\hline$E_{k a 1}$ & Microclimatic conditions & $\sum\left\langle E_{k 1} E_{k 2}\right) / 2$ & 0,98 \\
\hline$E_{k a 2}$ & Physical factors & $\sum\left\langle E_{k 6, E_{k 7}}\right) / 2$ & 0,84 \\
\hline$E_{k a 3}$ & Psychological stress & $E_{k 8}$ & 0,83 \\
\hline$E_{k a 4}$ & Visual load & $\sum\left\langle E_{k 9,} E_{k 10}\right) / 2$ & 0,74 \\
\hline$E_{k a 5}$ & Workplace premises and elements & $\sum\left\langle E_{k 11,} E_{k 17}\right) / 7$ & 0,96 \\
\hline$E_{k a b}$ & Workplace maintenance & $\sum\left\langle E_{k 18,} E_{k 19}\right) / 2$ & 0,74 \\
\hline
\end{tabular}

Source: authors

The resulting ergacity of the workplace under assessment was determined as $E s=$ 0,85 . It means, the risk of the workplace can be derived as $R s=0,15(R s=1-E s)$ and it can be stated that the workplace of the screener evaluated in the experiment is included in the fourth class of ergacity, referred to as "normal risk" (Král, 2001).

It can also be concluded from the above that the most upcoming operating optimum is the Microclimatic conditions category and the premises and elements of the workplace, in particular criteria air humidity, air temperature, workplace floor, layout of the workplace, colour and surface solutions of workplace materials, office chair and workplace background. Conversely, visual load and workplace maintenance can be assessed as the least satisfactory, mainly due to an inadequate CRT monitor without adjusting the inclination and adaptation to operators of different growth and needs.

The implementation of the experiment also pointed to the necessity to modify some defined input data of the Methodology because they are irrelevant for the evaluated workplaces and the values would positively distort the final assessment (eg volume per worker). Therefore, the selected parameters have been eliminated, others have been modified to scale the values they can acquire. Such revised data is already part of the final text of the Methodology and this paper. In summary it can be stated that the methodology is applicable and does not have formal shortcomings.

\section{Discussion}


Despite the maximum effort to create an objective tool for assessing the impact of ergonomic factors on the performance and reliability of the security screener, the authors are aware of several risks that should be taken into account when applying it:

1 Expert analysis of the assessment of ergatic significance, ie the relation of the assessed parameter to the assumed correlation rate with concentration, performance or possible error rate in performing the assigned work activities of the security screener in the human-machine-environment system, was performed on a sample of experts from different professions related to the topic of the research. However, it's clear that the results could have been somewhat different in consultation with other experts.

2 The methodology assesses complex workplaces within the organization. In the case of the assessment of multiple screening points within a company or an airport terminal, some values may be the same - for example workplace background or workplace rotation frequency, breaks, etc. These values can thus reduce the differences in the results of the individual workplaces Es.

3 One of the major factors influencing the psychological well-being of screening operators are passengers. Specifically, their quantity, queues, behaviour, noise, discipline, etc. This factor is not developed in the work, because it was not its goal. For further research, however, it is one of the key factors to be addressed.

4 Validation of ergonomic optimization is a long-term process. Therefore, if the airport operator adopts optimization measures based on the outputs of the Methodology, an immediate increase in performance and reliability cannot be expected. Although partial results can be observed, comprehensive "before/after" comparisons should be made no earlier than one year after implementation of the measure. In this respect, the limiting factor can be a high employee turnover rate, which, however, can be managed by a comprehensive assessment of the performance and reliability of the workplace rather than the individual operators.

\section{Conclusion}

In accordance with the above statements, the Methodology for assessing the impact of workplace ergonomic factors on airport security screener's reliability and performance has been created. Its uniqueness lies in a multidisciplinary approach combining the techniques of ergonomic assessment of the workplace and knowledge of air transport and the international airport environment in relation to the protection of civil aviation against acts of unlawful interference. Furthermore, a set of ninety measurable parameters of working environment, that could potentially affect the performance or reliability of the security screener, has been identified. These parameters were then clustered into nine criteria and six categories.

The necessary prerequisite without which the main aim could not be fulfilled was the fulfilment of the objectives of the partial ones, which at the same time aimed at enriching the scientific knowledge in the related scientific disciplines.

With the help of the eEPC model, the model of the security screening point was created, in which the processes related to cabin baggage detection are shown.

Furthermore, a set of ninety measurable parameters of working environment has been identified that could potentially affect the performance or reliability of the security screener. These parameters were then clustered into nine criteria and six categories. The parameters were obtained on the basis of literary research and discussions with experts 
involved in the field of air transport security, psychology of work, transport psychology, ergonomics and microclimatic conditions of the workplace.

It was necessary to determine how to use these parameters for further research. Criteria for the evaluation of the selected parameters were then set for subsequent expert analysis. The already existing HODERG method with the so-called ergatic significance was used as a basis, which was slightly modified for the purpose of this work.

Even the expert analysis itself has to be considered as a useful and key part in which the experts approached assess the correlation between the effects of the identified parameters and the concentration or potential reduction in the performance or reliability of the operators. On the basis of the outputs of this analysis we determined the weighting coefficients of all defined parameters.

For each of the parameters, the intervals of the values they can obtain and the degree of ergacity for the defined value intervals were determined.

The created Methodology is a comprehensive management tool that allows proactive assessment of security risks arising from the work environment in which the security screener performs activities aimed at suppressing acts of unlawful interference in air transport. As such, the Methodology may be included in the Security Management System (SeMS) in-house tools, which, together with the Safety Management System, is considered to be the state-of-the-art and most effective method for managing security risks in aeronautical companies by focusing on basic security management aspects, including assignment of responsibilities, risk assessment and optimization of in-house communications. Ergonomic checklists have existed until now, but they were not, by way of exception, oriented to a specific type of workplace and were used exclusively for the assessment of physical load or as a tool for assessing the workplace from the point of view of safety and health at work.

For the aerodrome operator, the implementation of the Methodology has the potential not only to increase the reliability of the screening, but it also brings secondary benefits, such as creating better comfort at the workplace, maintaining a higher level of mental and physical fitness, preventing health problems or minimizing fatigue. It could potentially be reflected in greater satisfaction and lower employee turnover.

One way to further improve the Methodology is to refine the weighting of the parameters by optimizing the points of ergatic significance by establishing cooperation with other experts. In the case of their correct selection and a greater number of evaluators, more correlation between the proposed system of assessment and the real status is assumed.

The application of the Methodology is also planned at other control points within Vaclav Havel Airport Prague (the plan is to carry out measurements at the new central security checkpoint in Terminal 2) as well as at other airports in the Czech Republic. The authors would like to extend the scope of the Methodology to selected foreign airports with the possibility of comparative analyses.

In order to simplify the recording of values and the calculation of the degree of ergacity of the categories, criteria and overall workplace, an electronic version of the guided Methodology is also planned with direct input of the measured values and automatic calculation. An interactive MS Excel spreadsheet document, a web interface, or a mobile application for the Android operating system come into consideration. The advantage of such a solution is first of all easy accessibility and ease of use.

The further research should be directed to the analysis of psychic conditions and factors that can affect the mental state of the screening operators. These include, for example, the effects of passenger behaviour, the fatigue curve, out-of-work psychological stress, motivation factors, etc. The proposed procedures should also be applicable after 
minor modifications to implement optimization measure in other transport sectors as well as in other critical infrastructure objects where the security of objects and premises are being secured through security screening, such as courts, prison buildings, nuclear power plants, sports stadiums, government buildings, etc. Here, it's needed to consider adjusting the parameters in the evaluation checklists.

\section{References}

1. ACI Europe (2015). Policy Fast Facts. [online]. Available at: https://www.acieurope.org/policy/fast-facts.html/

2. Banks, C. G., Mosier, K., Robertson, M., Honan, M., \& Cascio, W. (2017). Enhancing Business Effectiveness and Worker Sustainability Through HFE. In Proceedings of the Human Factors and Ergonomics Society Annual Meeting (Vol. 61, No. 1, pp. 890-893). Sage CA: Los Angeles, CA: SAGE Publications.

3. Bemosa (2013). Bemosa - Behaviour Modelling for Security in Airports [online]. Available at: http://bemosa.technion.ac.il/

4. Croucher, R., et al. (2013). Can better working conditions improve the performance of SMEs?: an international literature review. Geneva: International Labour Office.

5. Drahotský, I., \& Zýka, J. (2014). Factors Affecting Working Environment of Airport Security Staff. In. Sborník XI. Mezinárodní vedecké konferencie - Nové Trendy rozvoja letectva 2014. Košice: Letecká fakulta, Technická univerzita v Košiciach. 11. - 12. September 2014.

6. European agency for safety and health at work (2009). The human machine interface as an emerging risk. European Agency for Safety and Health at Work [online]. Available at: https://osha.europa.eu/en/publications/ literature_reviews/HMI_emerging_risk

7. European agency for safety and health at work (2013). Priorities for occupational safety and health research in Europe: 2013-2020. European Agency for Safety and Health at Work.

8. Hu, Z., Yi, C., Hao, J., Qiao, X., \& Guo, X. (2018). Comparative Study on the Effects of Lighting on Cognitive Ergonomics in Single and Multi-Working Modes. NeuroQuantology, 16(5).

9. IATA (2013). Joint Press Release: ACI and IATA Collaborate to Deliver Smart Security. [online]. Available at: http://www.iata.org/pressroom/pr/Pages/201312-12-02.aspx.

10. IATA (2014). New IATA Passenger Forecast Reveals Fast-Growing Markets of the Future: 2014. [online]. Available at: http://www.iata.org/ pressroom/ pr/Pages/2014-10-16-01.aspx

11. IATA (2016). IATA Annual Review. [online]. Available at: http://www.iata.org/publications/Pages/annual-review.aspx.

12. Kittinger, R., \& Bender, J. (2015). Methods for Determining the Role of Fatigue and Cognitive Load on Behavior Detection Officers (BDOs) Performance in the Field. In International Conference on Augmented Cognition (pp. 36-43). Springer, Cham.

13. Král, M. (2001). Metody a techniky užité v ergonomii. Praha: Výzkumný ústav bezpečnosti práce.

14. Moore, A. (2001). Workplace Ergonomics Program [online]. Virginia Polytechnic Institute and State University. Environmental, Health and Safety 
Services,

http://www.ehss.vt.edu/uploaded_docs/200709121634510.workplace_ergonomi cs july2001.pdf.

15. Oxley, D., \& Jain, Ch. (2015). Global Air Passenger Markets: Riding Out Periods of Turbulence. The Travel \& Tourism Competitiveness Report 2015 [online]. Available at: https://www.iata.org/publications/economicbriefings/WEF_TTCR_Chapter1.4_2015.pdf

16. Skřehot, P. A., et al. (2015). Ergonomická rizika a pracovní podmínky operátorů v ř́dicích centrech. In: Sborník přednášek Bezpečnost a ochrana zdraví při práci 2015. Ostrava: Vysoká škola báňská - Technická univerzita Ostrava.

17. Stolk, Ch., et al. (2012). Management of psychosocial risks at work: an analysis of the findings of the European Survey of Enterprises on New and Emerging Risks (ESENER). Luxembourg: Publications Office of the European Union.

18. Svaz průmyslu a dopravy České republiky 2004. Rámcová dohoda o stresu spojeném $s$ prací. [online]. Available at: http://www.spcr.cz/cz/eu/esd/esd_stres.pdf

19. Trevelyan, J. P. (2014). The making of an expert engineer: How to have a wonderful career creating a better world and spending lots of money belonging to other people.

20. Van der Voordt, T., \& Jensen, P. A. (2017). Benchmarking of workplace performance. In ERES 2017: 24th Annual Conference of the European Real Estate Society.

\section{Brief description of Author/Authors:}

Ing. Jan Zýka, Ph.D.

Department of Air Transport, University College of Business in Prague, Spálená 14, 110 00 Prague, Czech Republic, zyka@vso-praha.eu. Jan Zýka has been working as the head of the Department of Air Transport at the University College of Business in Prague with specialisation with Air Traffic Services, Air Transport and Aviation Security. He graduated from Ph.D. studies at the University of Pardubice.

doc. Ing. Ivo Drahotský, Ph.D.

Department of Transport Management, Marketing and Logistics, University of Pardubice, Studentská 95, 53210 Pardubice, Czech Republic. Ivo Drahotský has been working as the associated professor of the Department of Transport Management, Marketing and Logistics at the University of Pardubice with specialisation with transport safety and security. 